\section{How do Polish and Indonesian disclose in Facebook?}

\section{Differences in online self-disclosure, need for popularity, need to belong and self-esteem}

\section{How do Polish and Indonesian disclose in Facebook?

\section{Rahkman Ardi}

Department of Personality and Social Psychology, Universitas Airlangga, Surabaya, Indonesia and Faculty of Psychology, University of Warsaw, Warsaw, Poland

Dominika Maison

Department of Psychology, University of Warsaw, Warsaw, Poland

\begin{abstract}
Purpose - The purpose of this study is to explain cross-cultural differences in online self-disclosure (SD) between Indonesians, who live in a highly collectivist culture, and Poles - a hierarchical individualist culture. Various psychological factors have been taken into consideration, such as the need for popularity (NfP), the need to belong (NtB) and self-esteem (SE).

Design/methodology/approach - This study was designed as a quantitative study. First, a one-way ANOVA was performed to compare online SD and specific behaviours online between Indonesians and Poles. Second, correlational analysis between online SD and other psychological factors (NfP, NtB, SE) was conducted.

Findings - Indonesians were more likely than Poles to disclose information on Facebook. On the other hand, Poles showed a tendency to disclose more positive content than Indonesians. It was also found that SE was significantly correlated with positive content of online SD for both countries. Furthermore, online SD on Facebook is more closely associated with NfP than NtB.

Research limitations/implications - This study possesses several limitations in regard to the lack of generalization; this is due to the choice in scales and the sampling procedure. Thereby, further studies must take into consideration the proportion of genders, the differences in the construction of the "self" between individualist and collectivist cultures and the interpretation of culture orientation based on the primary data. Furthermore, several results related to the online SD would need to be verified by further studies to get a holistic explanation.

Originality/value - The current research is for all means and purposes original, as it investigates the differences of online behaviours between cultures - Polish and Indonesian - basing on the premise that there are crucial differences between collectivist and individualist cultures. No prior articles attempted the comparison between those nationalities in online behaviour.
\end{abstract}

Keywords Self-esteem, Indonesian, Need for popularity, Need to belong, Online self-disclosure,

Polish

Paper type Research paper

\section{Introduction}

Almost all online users, especially young people, are gathered within several of the social networking sites (SNS), especially on Facebook. Most recent statistics claim that more than a billion active users around the world spend their time on Facebook. The
Received 31 January 2014

Revised 4 April 2014

Accepted 8 April 2014

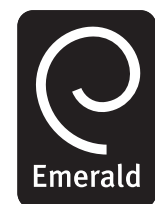

Journal of Information, Communication and Ethics in Society

Vol. 12 No. 3, 2014 pp. $195-218$

(C) Emerald Group Publishing Limited 1477-996X

DOI 10.1108/JICES-01-2014-0006 
JICES

12,3

196 immense popularity makes this site the single greatest traffic generator among the SNS. Statistics presented by Go-gulf.com (2011) show that in just 60 seconds there are $>695$ thousands status updates, 79,364 new wall posts and around 510,000 comments.

Those facts prove that Facebook has become a site where people share and post everything, mainly pertinent to their lives. Numerous studies show that SNS usage has given birth to a new fashion: people share intimate and private information publicly (Whitty and Joinson, 2009).

Online behaviour has been studied by social scientist since the development of computer-mediated communication (CMC) and SNS (Turkle, 1995; Whitty and Joinson, 2009). However, few studies investigate the differences in online behaviour between cultures, especially regarding psychological factors and motives for using SNS. Even cross-cultural studies related to SNS behaviour mostly cover differences in online behaviours between users in the USA (Hargittai, 2008), Western Europe (Vasalou et al., 2010) and Eastern Asia (Ardichvili et al., 2006; Gretzel et al., 2008), whereas Indonesians and Poles also have specific characteristics regarding their respective histories and cultures, as well as their own prominent patterns of online behaviours.

According to the report of Socialbakers (2013), the number of Facebook users in Indonesia is ranked first in Southeast Asia. This amount follows the user count in only the USA, India and Brazil. Based on same data, Poland has reached $>10$ million users, which makes Poland the seventh biggest Facebook participant in Europe after UK, Turkey, France, Germany, Italy and Spain. Therefore, Poland is considered to be the largest Facebook user in Central and Eastern Europe.

The Polish share a rather individualist type of culture (Hofstede, 2014b), though the effect of the bygone Communist regime, superseded 25 years ago, has left a unique characteristic on this individualist culture, distinguishing Poland among other Western-type societies (Boski, 2006). On the other side of the spectrum, Indonesians are considered to be the most collectivist culture in Southeast Asia, even moreso than China and India (Hofstede, 2014a).

However, there is a need for more cross-cultural studies, especially in regard to the interpersonal effect of the online media on information disclosure and the emergent psychological consequences of SNS use, such as the need for popularity (NfP), the NtB and self-esteem (SE) of the users.

A study conducted by Utz et al. (2012) explicitly stressed the role that NfP plays in predicting the range of SNS behaviours (such as profile enhancement and the disclosure of feelings); the study was conducted using the data obtained from Dutch Facebook users. NfP was proven to be the strongest predictor for estimating the range of SNS behaviours, even more prevalent than NtB and SE.

Additionally, Gangadharbatla (2008) found that Facebook use is motivated by NtB, using a sample consisting of students of one of the universities in the USA (Gangadharbatla, 2008). Day (2013) also implied that people were more likely to disclose positive aspects of personal information to fulfil their need to belong. Furthermore, Forest and Wood (2012) noted that Facebook provides a space for self-disclosure (SD) for people with low SE.

A majority of studies on Facebook use and online SD do not focus on significant differences associated with psychological factors, such as the NfP, NtB and SE, between Southeast Asian collectivist and Eastern European individualist cultures. There are several different components of the "self" among cultures (Markus and Kitayama, 1991); 
those include influencing the pattern of communication, disclosure and expression (Andersen, 2007) and making discrepancies of meaning construction of SE (Diener and Diener, 1995; Tafarodi and Walters, 1999). Diener and Diener (1995) claim that people in individualist cultures appear to value and like themselves more compared to those stemming from collectivist cultures. Similarly, there are different means to maintaining social relations across cultures, which influences the respective degrees of NtB and NfP.

The current research is aimed to explore cross-cultural differences among Facebook users in Poland and Indonesia - two countries with two different cultures, where Facebook plays an important role as a social medium. The study specifically covered the differences related to several dimensions of online SD in connection with psychological factors, such as NtB, NfP and SE. Those factors were suspected to have a strong correlation with online SD, as previous research showed (Utz et al., 2012; Gangardhabatla, 2008; Nadkarni and Hofmann, 2012; Forest and Wood, 2012).

Additionally, we suspected that there would be differences between those nationalities when it comes to accessibility/availability of the profile page, which is correlated to online SD tendencies. Moreover, several online behavioural indicators, such as the frequency of writing on the wall, commenting, uploading pictures and the number of friends, were also investigated in correspondence with the differences among the nationalities.

Finally, it is believed that investigating the chosen psychological factors and differences in online behaviour between these two countries would reveal a specific pattern of usage motives, as well as online SD patterns, usually rarely taken into consideration in social psychology research.

Further goals of this research included the general understanding of online behaviours in SNS within both hierarchical - individualist and hierarchical-collectivist cultures. We argued that online behaviour between the Polish and Indonesians had never been similar, particularly due to differences in social values and background.

\section{Literature review}

\subsection{Indonesian and Polish cultures}

Individualism and collectivism constitute the fundamental dimensions for crosscultural differences (Andersen, 2007). The two dimensions could demonstrate how core values of specific societies influence both expression and modes for verbal and non-verbal communication. Individualist cultures usually emphasize their value of space, privacy, emotional expression and personal choice. On the other side of the spectrum, collectivist cultures emphasize contact, togetherness and control of individual expression of emotion, particularly when it comes to expression of negative emotion (Andersen, 2007). Western European and Northern American countries mostly fall into the category of individualist cultures, while collectivist cultures are commonly found among Asian countries.

Indonesia, an Eastern culture, is considered to be one of the most collectivist-oriented, with its high-context and strongly hierarchical culture. Indonesian culture generally favours spiral logic and implication in communication (Reisinger and Turner, 1997). According to Markus and Kitayama (1991), people in collectivist cultures are more likely to have interdependent self-construals. The interdependent of self-construal is not self-centred, but based on context and situation. For instance, Southeast Asians, such as Indonesians, are more likely to neutralize affective displays in public by avoiding to
How do Polish and Indonesian disclose in Facebook?

197 
JICES

12,3

198 express their feelings and thoughts openly; this serves to maintain harmony and to prevent disagreements or unpleasant interchanges, especially with consideration to significant others (Mathews, 2000). Indonesians, belonging to a collectivist culture, have many rules pertaining to social interaction; they also emphasize conformity in groups, avoid disagreements and public criticism and strive to maintain good social interaction (Argyle et al., 1986; Reisinger and Turner, 1997).

On the other hand, Poland is considered to be a country with intermediate levels of both collectivism and individualism (Forbes et al., 2009). The influence of Poland's eastern neighbour, the power of the Catholic church and the effect of history as the Soviet Union's satellite country - these combined factors have created a balanced mix of individualist and collectivist elements within the Polish culture (Boski, 2006). However, according to the study by Hofstede, 2014b, Poland has already incorporated several Western ideas, which are more egocentric and individualist. Markus and Kitayama (1991) explained that people in individualist cultures are likely to create independent construals of the self; as such, they tend to be more direct and frank because the primary reference of the self is based on their own thoughts, feelings and actions (Markus and Kitayama, 1991).

The uniqueness of Polish individualist culture compared to other Western cultures stems from this combination of an egocentric character with a hierarchical society, creating specific features in relationships between people; in Polish culture, communication may be tenuous, sensitive and uneasy at the beginning of a relationship, but become intense and meaningful with time (Hofstede, 2014b).

\subsection{Online self-disclosure}

$\mathrm{SD}$ is defined as "any messages about the self that an individual communicates to another" (Gibbs et al., 2006, p. 155; Wheeles and Grotz, 1976). According to the Jourard and Lasakow (1958), it is the process of making the other know about ourself. Whitty and Joinson (2009) outlined several purposes of SD, e.g.: increasing mutual understanding, building trust, strengthening relationships (either friendships or romantic relationships), enhancing bonds between group members and serving the purpose of authentication in organizations.

There are several strategies as to how people choose to disclose information in regard to their interaction motivation (i.e. people in trusting and close relationships disclose more frequently), the intimacy of the information and the level of honesty (Wheeless and Grotz, 1976). In addition, Rubin et al. (1993) indicated that people who have higher motive of affinity-seeking in relationship are more likely to share positive content, are more intentional and display a higher level of honesty in SD. Furthermore, a study by Forgas (2011) pointed out that people in positive moods disclose more intimate, positive, varied and abstract information. Predictably, people in negative moods display less intimate, more negative, more cautious, reciprocal and self-protective disclosure patterns.

Wheeless and Grotz (1976) mentioned several dimensions of SD - the amount, depth/ intimacy and negative - positive content (valence) of the information disclosed. The amount of SD is related in the frequency of disclosure; valence of SD is determined by whether the content of disclosure is understood to be negative or positive and the depth/ intimacy of SD is related to the degree of control of the depth or intimacy the individual discloses of him/herself. 
Various research studies have mentioned how the Internet has effectively impacted self-disclosure, especially given the different nature of online and face-to-face $(\mathrm{FtF})$ communication; anonymity, accessibility and affordability of the Internet have effectively shaped current interaction patterns and disclosure behaviours. Compared to face-to-face encounters, people significantly disclose more in an online environment (Tidwell and Walther, 2002; Parks and Floyd, 1996; Joinson, 2001). In addition, Tidwell and Walther (2002) explain that the higher frequency of online SD is driven by the people's motivation to reduce uncertainty.

However, users are also motivated to have an accurate view of other users' identity (Whitty and Joinson, 2009). The lack of visible gestures, eye contact, facial expression and other non-verbal cues, prompts attempts at increasing predictability in SNS interaction (Whitty and Joinson, 2009). Therefore, the limitations of the online media make the users adapt their uncertainty-reducing behaviour by asking more direct, intimate and/or even more undesirable questions (Whitty and Joinson, 2009; Tidwell and Walther, 2002).

Furthermore, the anonymity on the Internet helps loosen inhibitions while communicating online. People communicate more freely in online settings than they do in FtF communication. This phenomenon is known as the "disinhibition" effect and is defined as the likelihood of people to split their intrapsychic world into two different realities (Suler, 2004).

Both people living in collectivist cultures, who have to deal with many rules of maintaining social relationships, and those living in individualist cultures, promoting more self-centred attitudes, are able to behave differently when disclosing information on the Internet; this is in large part due to the disinhibition effect which presents itself in online circumstances.

A study by Gretzel et al. (2008) showed that people in collectivist countries, such as China, are more likely to value networking and relationship-building online, which prompts higher levels of interactions on websites. On the other hand, German people, who come from an individualist and self-centred culture, are less likely to engage in activities in social media due to concerns for their privacy.

Moreover, a study by Vasalou et al. (2010) showed that status updates on Facebook were most important for the US users (followed by users from the UK, Italy, Greece and France), but activities connected to photographs (i.e. tagging, being tagged, viewing, sharing/posting photographs) are most important for the UK users compared to other countries examined. French users visited Facebook less frequently compared to the others and considered updating their status and engaging in photograph-related activities as less important.

However, culture and society contribute to the formation of various defensive mechanisms and behavioural tendencies specific to the Internet. How people actually present themselves and disclose information by means of representational codes on the Internet may be a reflection of personal expectations, wishes, needs as well as social backgrounds (Suler, 2004). Papacharissi (2009) indicated that CMC, such as blogging, is used to gratify some of the interpersonal and mediated needs. Interpersonal needs, which are considered necessary for humans, are needs of expression, affection, inclusion and social interaction.

Mediated needs are the needs of surveillance, information-seeking, pleasure and relaxation (Papacharissi, 2009). Hence, SNS provide opportunities for individuals who
How do Polish and Indonesian disclose in Facebook? 
JICES

12,3

200 have grown up in cultures with strict norms or for those who are shy or reticent, to be braver in disclosing whatever and however they please in online settings, regardless of social rules and authorities. People may widen their friendship network by using SNS without feeling anxious or worried, and at the same time, they may feel more accepted and improve their self-presentation (Becker and Stamp, 2005; Papacharissi, 2009; Gangadharbatla, 2008; Nadkarni and Hofmann, 2012).

In addition, Nadkarni and Hofmann (2012) assumed that members of individualist cultures tend to share a fair amount of personal information with their Facebook friends; this raises a potentially controversial issue, due to the greater need for self-presentation. On the other hand, members from collectivist cultures seemingly tend to have more frequent interactions and shape a strong and a closely knit network on Facebook due to their greater $\mathrm{NtB}$.

A study conducted by Ardichvili et al. (2006) presented different strategies of online disclosure between cultures with different levels of individualism and perception of power and hierarchy, but their study only focused on the different preferences for communication modes, knowledge seeking and information-sharing patterns. Hargittai (2008) suggested that culture and ethnicity influence the use of SNS especially between Caucasian, Hispanic, Afro-American, Asian-American and Native American groups, but their study was based on participants from one university in the USA. Vasalou et al. (2010) only compare motives for disclosure and online behaviours between several European countries and the USA.

Considering these assumptions, there are very few cross-cultural studies on online SD comparing different levels of individualism and collectivism, but at the same time, have relatively similar patterns of unequal distribution of power distance occur in societies such as the Polish and Indonesian. Therefore, this study aimed to explore the differences in online behaviours between Indonesians, belonging to a hierarchical collectivist culture and Poles, belonging to a hierarchical - individualist culture.

These key concepts lead to the following hypotheses of this study below:

H1. Indonesians, who live in a collectivist culture, will show more online SD - i.e. larger amount of shared information, deeper intimacy and more positive content of disclosure - on Facebook than the Polish users.

H2. Furthermore, Indonesians will be more likely to display more intense behaviours on Facebook than Poles, such as providing accessible profile information, showing higher online frequency of disclosure: writing on their walls, commenting, uploading; they will also have a larger number of friends.

\subsection{Need for popularity}

$\mathrm{NfP}$ is defined as a tendency to manage a specific impression aimed at gaining popularity among others (Utz et al., 2012). Christofedes et al. (2009) noted that NfP tends to be the driving force behind the disclosure of information among the youth on Facebook.

"Being popular" here means to not only be effective in using social skills but also to display several characteristics, such as likeability, ability to maintain friendships and trendsetting among others (Debruyn and Van den Boom, 2005). Popular individuals tend to be more attractive, warmer, friendlier and highly visible (De Bruyn and Van den Boom, 2005). Overall, popularity on the Internet could be defined by network 
centrality - indicating the degree of how central is the position of a given individual in the network (Valente et al., 2004), by being liked or attractive among others (Zywica and Danowski, 2008).

A study by Becker and Stamp (2005) claimed that people in CMC are often motivated by their desires for social acceptance, relationship maintenance and identity experimentation; all of these motivations often appeared to be interconnected. Several studies also showed that being connected and visible in online networks is perceived as an important factor to reach popularity among the younger people (Boyd, 2008; Christofedes et al., 2009). Additionally, Zywica and Danowski (2008) demonstrated that Facebook provides opportunities for the users to create any profile, which provides possibilities for exaggeration and fabrication of information to improve popularity.

The nature of the Internet makes it possible and easy for people to use impression management to control and construct their own image (Leary and Kowalsky, 1990) as well as choose what they want to disclose (Joinson, 2001) to gain more popularity (Christofedes et al., 2009), likeability, acceptance (Becker and Stamp, 2005) and high visibility (Haferkamp and Krämer, 2009) in online interactions. The ease with which users control selective self-presentation in CMC as well as the convenience of SNS to reach large audiences with just one mouse click, make SNS ideal places for individuals who have high NfP (Utz et al., 2012).

There are several studies that concentrate on NfP and online SD showing positive correlation (Christofedes et al., 2009; Utz et al., 2012), but only very small number of cross-cultural studies focused on the association between these variables. We argue that there are different patterns of association between the Indonesian and Polish in connection to NfP and several dimensions of online SD (amount, depth/intimacy and positive content) considering that:

- popularity accelerates acceptance towards others (De Bruyn and Van Den Boom, 2005; Bukowski and Hoza, 1989); and

- the desire to be accepted is more salient in collectivist compared to individualist cultures (Andersen, 2007).

This explanation allows for the following hypothesis:

H3. People with higher NfP will show more online SD (i.e. larger amounts of shared information, deeper intimacy and more positive content of disclosure for both Indonesians and Poles).

\subsection{Need to belong}

$\mathrm{NtB}$ is defined as the need for social acceptance (Baumeister and Leary, 1995). This need can be satisfied by fulfilling several criteria:

- frequent interactions, related to how often individuals engage in affectively pleasant, repetitive interactions with the same individuals; and

- the interactions need to form a temporally stable and enduring framework of affective care for each other's welfare (Baumeister and Leary, 1995, p. 497).

According to Baumeister and Leary (1995), repeated interaction with the same people is more satisfactory compared to interactions with a constantly changing sequence of partners. Hence, NtB is more related to the degree of acceptance in a relatively small
How do Polish and Indonesian disclose in Facebook?

201 
JICES

12,3

202

group of peers with strong ties among members, which have deeper, more significant interactions (Utz et al., 2012). Santor et al. (2000) indicated this was indicative for the youth, chiefly driven by the need for acceptance in their peer groups.

Several studies showed that the NtB is associated with the use of SNS (Gangadharbatla, 2008; Nadkarni and Hofmann, 2012) and willingness to joint SNS (Gangadharbatla, 2008). SNS provide people with easily available platforms for attaining social approval, expressing opinions and influencing others, all in accordance with their motivation by the NtB (Gangadharbatla, 2008). Furthermore, by using the unique characteristics of SNS, people can take advantage to develop and maintain relationships with others (Walther, 2007; Tidwell and Walther, 2002) and also increase acceptance among peers (Nadkarni and Hofmann, 2012) by maintaining close contact with their friends, irrespective of temporal and physical space (Gangadharbatla, 2008).

Becker and Stamp (2005) noted that users with higher need for social acceptance usually made specific adjustments while communicating with others. Skillful communication and tactical SD in $\mathrm{CMC}$ are needed to attain social acceptance and successfully maintain relationships (Becker and Stamp, 2005). Additionally, Day (2013) found that there is tendency of positive SD in Facebook users by controlling their disclosure behaviour cautiously to fulfil their NtB and to project a socially desirable "self" based on their audience.

Studies related to the NtB and its connection to SNS use, as well as online SD, have mostly been conducted within a single culture (Gangadharbatla, 2008; Nadkarni and Hofmann, 2012; Day, 2013). However, systematic studies comparing hierarchichal collectivist and hierarchical - individualist cultures are relatively rare. In our own study, we suggest that there are different patterns of $\mathrm{NtB}$ and several dimensions of online SD (amount, depth/intimacy and positive content) in Indonesian and Polish cultures, considering that maintaining harmony and emphasizing conformity are more salient in collectivist rather than individualist cultures (Argyle et al., 1986; Reisinger and Turner, 1997).

Which leads to the following hypothesis:

H4. People with higher NtB will show more online SD (i.e. larger amounts of shared information, deeper intimacy and more positive content of disclosure for both Indonesians and Poles).

\subsection{Self-esteem}

People with low SE tend to be more uneasy with disclosing information on themselves than people with high self-esteem; therefore, online communication platforms, such as Facebook, may be valuable for individuals with low-self esteem as means to express themselves (Forest and Wood, 2012). Thus, beside self-exploration and social facilitation, SNS could be used as a medium for social compensation (Valkenburg et al., 2005).

Social compensation as a motive enables people who are unable to develop friendships in FtF encounters to compensate and substitute their need by using SNS (Valkenburg et al., 2005; Zywica and Danowski, 2008). Visual anonymity in SNS makes those individuals feel safer to express themselves - due mostly to the lack of need for physical appearance and visual cues in online settings - which lessens the anxiety of potential condemnation or rejection (Qian and Scott, 2007) and makes people feel less shy compared to FtF interaction (McKenna et al., 2002; McKenna and Bargh, 1998). This provides people with low SE with opportunities to disclose information on themselves 
more frequently (Forest and Wood, 2012) and prompts increased display of SNS activity (Mehdizadeh, 2010).

Krämer and Winter's (2008) study showed a different effect - according to their results, SNS activity is not correlated to SE in German social media (StudiVZ). However, this study did not yield conclusive results and needed further research to observe the nature of a specific SNS, which was used in research (Krämer and Winter, 2008).

Forest and Wood (2012) demonstrated the differences in the content of expression in SNS by people with low and high self-esteem. People with lower SE share more negative information than people with higher SE (Forest and Wood, 2012). Additionally, Gonzales and Hancock (2011) stated that exposure of information on a Facebook profile improves self-esteem, as editing online profile information strengthens the awareness of the optimal self (Gonzales and Hancock, 2011).

However, there are not many studies concerning the relationship of SE and online SD across cultures, especially between hierarchical - individualist and hierarchical collectivist cultures. Therefore, this study aimed at examining the cross-cultural differences between Indonesian and Polish cultures in terms of relationship between SE and online SD, assuming that collectivists tend to have lower SE compared to the individualists (Tafarodi and Walters, 1999).

Based on these theoretical frameworks, several hypotheses were constructed as follows:

H5. People with lower SE will show more online SD (i.e. larger amounts of shared information, deeper intimacy and more positive content of disclosure for both Indonesians and Poles).

\subsection{Profile availability}

When an individual is registering on Facebook, they need to create a user profile; for instance, name, gender and date of birth can be available for access by others. Users can also provide additional information about themselves on their profile, such as their home town, telephone number, address, e-mail address, instant messaging address, employment and education, personal information, hobbies or pictures. Availability of the profile can be controlled, so that it could be visible to the general public or just to a limited group of users.

A study conducted by ConsumerReports.org (2012) indicated that around 28 per cent of users do not use any privacy setting and share all, or almost all, information on Facebook without filtering it through the friendship network. In addition, just 37 per cent of users use privacy setting on their Facebook page (ConsumerReports.org, 2012).

Furthermore, a study by Govani and Pashley (2005) also showed that even though users know and understand the ways to limit the visibility and accessibility of their personal information, they do not protect the information. By limiting the availability, visibility and accessibility of their personal information on their profile page, users may also prevent the further disclosure of personal information, e.g. writing on wall (status updates), comments and others.

However, the limitations of the $\mathrm{CMC}$ concerning the anonymity and the absence of non-verbal cues may enable the disclosure of more intimate and even sensitive information in online encounters, moreso than in real-life communication (Sheldon, 2009; McKenna and Bargh, 1998; Chesney, 2005; Whitty and Joinson, 2009).
How do Polish and Indonesian disclose in Facebook?

203 
JICES

12,3

204
In line with these results, Chesney's (2005) study also showed that Internet users are more likely to reveal their most personal thoughts and experiences online. In addition, Nosko et al. (2010) reported that Facebook users disclosed around 25 per cent of information containing highly personal, sensitive and potentially stigmatizing information.

However, cross-cultural studies seldom focus on the investigation of profile accessibility between hierarchical - individualist and hierarchical - collectivist cultures. We proposed that there were distinct tendencies between Indonesians and the Polish in respect of profile accessibility and online SD, especially presuming that individualists are more likely to have control over privacy than collectivists (Andersen, 2007).

Thus, the final hypothesis for this research is as follows:

H6. People with higher availability of profile information will show more SD (i.e. larger amounts of shared information and deeper intimacy for both Indonesians and Poles).

\section{Methods}

This study was performed to answer the following research questions:

$R Q 1$. What is the difference between Indonesians and Poles in terms of online SD, profile information availability, number of friends and online frequency of disclosure behaviour on Facebook?

$R Q 2$. What is the relationship of online $\mathrm{SD}$ with $\mathrm{NfP}, \mathrm{NtB}, \mathrm{SE}$ and profile availability between Indonesians and Poles?

Poland and Indonesia were chosen as participants because Polish culture represents the characteristic of a Western hierarchical - individualist culture, whereas the Indonesian culture represents the Eastern hierarchical-collectivist culture. Cross-cultural studies rarely focus on comparing between these two characteristics. Most studies assume that Western cultures are more likely to be egalitarian and individualist without considering the existence of another dimension in Eastern and Central European cultures. Furthermore, both countries were also considered to be engaged users of SNS (Socialbakers, 2013).

The study was carried out using an online survey for distributing questionnaires. The survey was conducted between March and June 2013. The data were gathered with the use of the snowball sampling procedure and distributed through Facebook groups of several universities in Indonesia and Poland. Snowball sampling was used as an efficient method of reaching the population of Facebook users in the two target countries; moreover, the method is simple, cost-efficient and easily used using Facebook as a platform.

The sample $(N=646)$ consisted of 300 Poles and 346 Indonesians. The participants were dominantly female in both Indonesian (59 per cent) and Polish (83 per cent) populaces. The Polish participants were predominantly (69.7 per cent) students: 23.6 per cent were employed and 2 per cent unemployed. On the other hand, of the Indonesian participants, 60.7 per cent of cases were students: 31.8 per cent were employed and 4 per cent unemployed. The average age among the Indonesian participants was 26.48 $(\sigma=6.98)$ and among the Polish, $24.1(\sigma=5.64)$. Of the Indonesians, 80.7 per cent and of the Poles 90.3 per cent were online on Facebook on a daily basis.

The survey consisted of two sections: the first section provided a question concerning the mother tongue to split the participants into groups based on their native languages and the second section consisted of basic demographical questions, followed by scales 
concerning their personality and behavioural patterns. Several scales were used in the study: SD, NtB, NfP and SE and profile availability.

The revised SD scale, developed by Wheeless and Grotz (1976), was adapted for this study to measure what an individual reveals about him/herself on Facebook, especially in the dimensions of the amount ( 7 items, $\alpha=0.77$ ), depth/intimacy (5 items, $\alpha=0,82$ ) and valence/negative - positive contents ( 7 items, $\alpha=0.71$ ) of the information.

The NfP scale (12 items, $\alpha=0.92$ ), used for measuring motivation of a given individual to conform and the desire to be popular among peers (Santor et al., 2000), was used in this study. The NtB scale (10 items, $\alpha=0.80$ ) was used for measuring the need to be accepted in social contexts (Leary et al., 2012).

The SE scale $(\alpha=0.84)$ composed by Rosenberg (1965) was used for measuring self-esteem.

All factors were measured with 5-point Likert-type scales, where [1] = "strongly disagree" and [5] = "strongly agree".

Participants were also asked about the accessibility of 14 types of information shared on the Facebook profile (e.g.: name, address, relationship status, work profile, education profile, email, etc.), by choosing several options for each type of information: [1] = "not written", [2] = "private", [3] = "limited" and [4] = "public".

Frequency of writing on the wall, commenting and uploading were assessed and estimated by the users with the help of a Likert-type scale with the range between [0] = "never" to [5] = "very frequently."

Each participant was also asked about the total number of friend that he/she has on Facebook.

All questions and scales were translated into Indonesian and Polish and verified by four competent raters - two Poles and two Indonesians.

\section{Results}

One-way ANOVA was performed to compare the degrees of SD (in dimensions of the amount of information, depth/intimacy, valence/positive content) and behavioural factors (profile availability, frequency of writing on the wall, commenting and uploading and a number of friends) between Indonesian and Polish users.

As Table I demonstrates, statistically significant differences between Polish and Indonesians were found in variables as follows: amount of $\mathrm{SD}(F=78.13, p<0.001$, $\left.\eta^{2}=0.108\right)$, intimacy of SD $\left(F=51.26, p<0.001, \eta^{2}=0.149\right)$, positive content of SD $\left(F=18.63, p<0.001, \eta^{2}=0.028\right)$, profile availability $\left(F=82.04, p<0.001, \eta^{2}=0.113\right)$, frequency of writing on wall $\left(F=78.11, p<0.001, \eta^{2}=0.108\right)$, frequency of commenting $\left(F=22.3, p<0.05, \eta^{2}=0.108\right)$, frequency of uploading $(F=43.17, p<$ $\left.0.001, \eta^{2}=0.063\right)$ and the total number of friends $\left(F=334.653, p<0.001, \eta^{2}=0.344\right)$.

Although ANOVA results show that there were significant differences on positive $\mathrm{SD}$ and frequency of commenting between Indonesian and Polish, the effect sizes were small to modest. In those effects, the partial eta-squared were ranging from 0.02 to 0.03 . Furthermore, the amount of SD, profile availability, frequency of writing on the wall and frequency of uploading had medium sizes ranging from 0.06 to 0.1. Intimacy of SD and total friends had large size which partial eta-squared were ranging from 0.14 to 0.34 .

Pertaining to the first hypothesis (H1), Indonesians show more frequent online SD and have a higher degree of depth/intimacy of SD on Facebook than Poles. The Poles, however, are more likely to disclose positive content on Facebook compared to Indonesians. In
How do Polish and Indonesian disclose in Facebook?

205 


\begin{tabular}{|c|c|c|c|c|c|c|c|c|}
\hline \multirow{2}{*}{$\begin{array}{l}\text { JICES } \\
12,3\end{array}$} & \multicolumn{8}{|c|}{ Nationality } \\
\hline & Variables & df1 & df2 & $\begin{array}{l}\text { Mean }(\sigma) \\
\text { Indonesian }\end{array}$ & $\begin{array}{l}\text { Mean }(\sigma) \\
\text { Polish }\end{array}$ & $F$ & $p$ & $\eta^{2}$ \\
\hline \multirow[b]{3}{*}{206} & Amount of online SD & 1 & 644 & $2.54(0.66)$ & $2.04(0.77)$ & 78.13 & 0.0001 & 0.108 \\
\hline & Intimacy of online SD & 1 & 644 & $2.09(0.76)$ & $1.53(0.56)$ & 51.26 & 0.0001 & 0.149 \\
\hline & Positive content of & 1 & & $360(052)$ & $389(\Omega 67)$ & 1863 & 00001 & 0.028 \\
\hline & NfP & 1 & 644 & $2.16(0.67)$ & $1.58(0.59)$ & 133.45 & 0.0001 & 0.172 \\
\hline & $\mathrm{NtB}$ & 1 & 644 & $3.09(0.53)$ & $3.27(0.76)$ & 12.36 & 0.0001 & 0.019 \\
\hline & $\mathrm{SE}$ & 1 & 644 & $3.48(0.53)$ & $3.63(0.77)$ & 8.64 & 0.003 & 0.013 \\
\hline & Profile availability & 1 & 644 & $2.73(0.62)$ & $2.29(0.61)$ & 82.04 & 0.0001 & 0.113 \\
\hline Table I. & Frequency writing on wall & 1 & 644 & $3.83(1.85)$ & $2.64(1.51)$ & 78.11 & 0.0001 & 0.108 \\
\hline df, mean, standard & Frequency commenting & 1 & 644 & $4.66(1.81)$ & $3.99(1.76)$ & 22.3 & 0.0001 & 0.033 \\
\hline deviations $(\sigma)$, ANOVA & Frequency uploading & 1 & 644 & $2.45(1.45)$ & $1.77(1.11)$ & 43.17 & 0.0001 & 0.063 \\
\hline test and effect sizes & Total friends & 1 & 644 & 1124.88 (751.54) & 309.3 (183.02) & 334.653 & 0.0001 & 0.344 \\
\hline
\end{tabular}

connection to the second hypothesis (H2), Indonesians are more accessible in their profile availability. Indonesians also write on their walls, comment and upload more frequently and have a bigger number of friends in their networks compared to the Poles.

The third (H3), fourth (H4), fifth $(H 5)$ and sixth $(H 6)$ hypotheses were analysed by means of the Pearson correlation (Table II) and verified by the observed value of $z$ (Table III). The observed $z$-value was analysed to identify the significant differences in the strength of the correlations in similar variables across nationalities.

NfP and online SD were correlated differently between Indonesian and Polish users (cf. H3). For both Indonesian and Polish, NfP was positively and significantly correlated with SD in dimensions of the amount $\left(\mathrm{r}_{\mathrm{Ind}}=0.309, p=0.0001 ; \mathrm{r}_{\mathrm{Pol}}=0.203, p=0.0001\right)$ and intimacy $\left(\mathrm{r}_{\text {Ind }}=0.381, p=0.0001 ; \mathrm{r}_{\mathrm{Pol}}=0.17, p=0.003\right)$. Additionally, NfP was significantly correlated with positive contents of SD for the Indonesian users $\left(\mathrm{r}_{\text {Ind }}=-0.236, p=0.0001\right)$, but not for the Polish $\left(\mathrm{r}_{\mathrm{Pol}}=-0.026, p=0.649\right)$.

Furthermore, there were significant differences in the strength of correlation between depth/intimacy of online SD and $\operatorname{NfP}(z=3.70, p=0.000)$ as well as the positive content of online SD and NfP $(z=-2.70, p=0.006)$ among those nationalities. However, there was no statistically significant difference in the strength between the amount of online $\mathrm{SD}$ and NfP between Indonesians and Poles $(z=1.43, p=0.15)$.

$\mathrm{NtB}(H 4)$ showed almost no correlation with any of the dimensions of online SD for users from both countries $\left(\mathrm{r}_{\text {Ind depth/intimacy } \mathrm{SD}}=0.063, p=0.246 ; \mathrm{r}_{\mathrm{Pol} \text { depth/intimacy SD }}=\right.$ $\left.0.045, p=0.439 ; \mathrm{r}_{\text {Ind positive } \mathrm{SD}}=0.002, p=0.977 ; \mathrm{r}_{\mathrm{Pol} \text { positive } \mathrm{SD}}=0.087, p=0.132\right)$. The only exception was the correlation between $\mathrm{NtB}$ and the amount of online SD for Polish users, which were positively, albeit weakly correlated $\left(\mathrm{r}_{\text {Ind amount SD }}=0.085, p=0.115\right.$; $\mathrm{r}_{\mathrm{Pol} \text { amount } \mathrm{SD}}=0.120, p=0.038$ ). However, there were no statistically significant differences in the strength of the correlation coefficient of $\mathrm{NtB}$ with any of the dimensions of online SD for both nationalities - either for the amount of online SD $(z=-0.44, p=0.65)$, depth/intimacy $(z=0.23, p=0.82)$ or positive contents $(z=-0.84$, $p=0.39)$.

SE (H5) was positively correlated with the positive content of online SD both for the Indonesian and Polish users $\left(\mathrm{r}_{\text {Ind }}=0.385, p=0.0001 ; \mathrm{r}_{\mathrm{Pol}}=0.294, p=0.0001\right)$. 


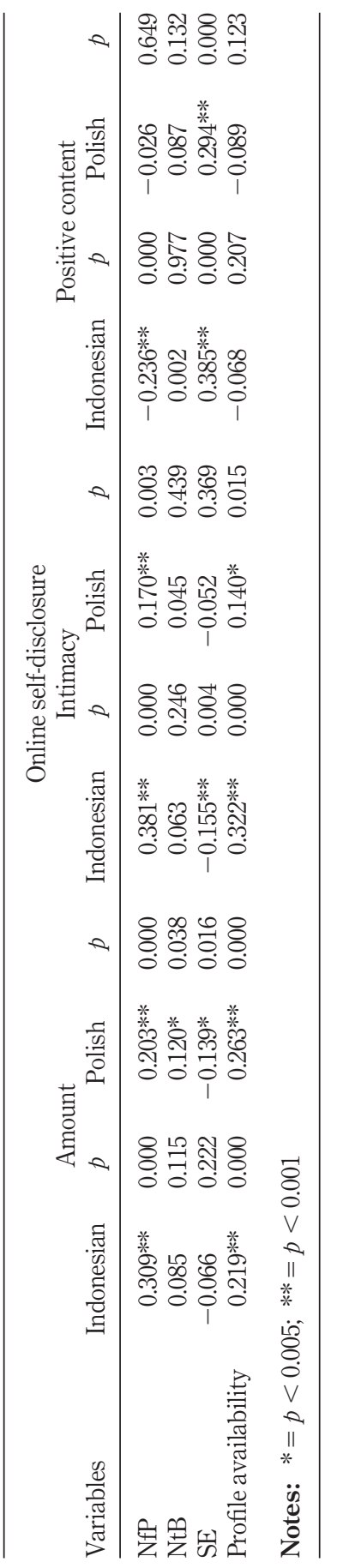

How do Polish and Indonesian disclose in Facebook?

207

Table II.

Pearson correlation and $p$-value across nation 
JICES

12,3

208

Table III.

$z$ observation and significant different between coefficient correlation across nation
Furthermore, for Indonesians, SE was negatively correlated with depth/intimacy of online $\mathrm{SD}\left(\mathrm{r}_{\text {Ind }}=-0.155, p=0.004\right)$, but no significant correlation was present with the amount of online SD ( $\left.\mathrm{r}_{\text {Ind }}=-0.066, p=0.222\right)$. For the Polish users, SE was negatively correlated with the amount of online SD $\left(\mathrm{r}_{\mathrm{Pol}}=-0.139, p=0.016\right)$, but not correlated with depth/intimacy of online SD $\left(\mathrm{r}_{\mathrm{Pol}}=-0.052, p=0.369\right)$. In general, there were no statistically significant differences in the strength of correlation coefficient of SE with any of the dimensions of online SD: the amount $(z=0.93, p=0.35)$, depth/intimacy $(z=-1.31, p=0.19)$ and positive content $(z=1.3, p=0.19)$ between the two nationalities.

Profile availability $(H 6)$ was positively correlated with the amount of shared information $\left(\mathrm{r}_{\text {Ind }}=0.219, p=0.0001 ; \mathrm{r}_{\mathrm{Pol}}=0.236 p=0.0001\right)$ and depth/intimacy of SD $\left(\mathrm{r}_{\text {Ind }}=0.322, p=0.0001\right)$ for both Indonesian and Polish users.

Moreover, there was no statistically significant difference between the strength of correlation coefficient of profile availability and the amount of $\mathrm{SD}(z=-0.59, p=0.55)$ of Indonesians and Poles. However, there was a statistically significant difference between the strength of correlation coefficient of profile availability and intimacy of SD $(z=2.43, p=0.01)$.

\section{Discussion}

Indonesians appear to disclose more information on Facebook than Poles. This was indicated by the higher mean of the amount of SD, frequency of writing on the wall, commenting and uploading. This finding may indicate that interpersonal and mediated needs in SNS are more strongly present in Indonesians compared to Poles. Papacharissi (2009) noted that people's motivation to engage in CMC is to gratify interpersonal needs, such as the identity expression and social connection as well as mediated needs, such as the need for surveillance, entertainment and escape.

In FtF encounters, collectivists are more likely to have many rules, especially those pertaining to various social norms and respecting people with authority. However, Facebook is a platform that provides freedom of expression due to visual anonymity (Suler, 2004). This may enable users in collectivist cultures, like Indonesian, to express themselves more freely in an online setting than they would do publicly or in front of a figure of authority. People do not need to be worried about their gestures, facial expression or voice when they disclose themselves in SNS, even if everyone knows about their identity. At the same time, they are also able to maintain and broaden their network.

Furthermore, this study has found that Poles appear to be less open to disclose personal information compared to the Indonesians. Profile pages of the Polish Facebook

\begin{tabular}{|c|c|c|c|c|c|c|}
\hline \multirow[b]{2}{*}{ Variables } & \multicolumn{2}{|c|}{ Amount } & \multicolumn{2}{|c|}{$\begin{array}{l}\text { Online SD } \\
\text { Intimacy }\end{array}$} & \multicolumn{2}{|c|}{ Positive content } \\
\hline & $z$ & $p$ & $Z$ & $p$ & $z$ & $p$ \\
\hline NfP & 1.43 & 0.15 & 3.70 & $0.000^{* *}$ & -2.70 & $0.006^{* *}$ \\
\hline $\mathrm{NtB}$ & -0.44 & 0.65 & 0.23 & 0.82 & -0.84 & 0.39 \\
\hline $\mathrm{SE}$ & 0.93 & 0.35 & -1.31 & 0.19 & 1.3 & 0.19 \\
\hline Profile availability & -0.59 & 0.55 & 2.43 & $0.01 *$ & 0.27 & 0.78 \\
\hline
\end{tabular}

Notes: $*=p<0.05 ; * *=p<0.01$ 
users were less likely to be accessible than those of Indonesian users. Poles generally shared more positive contents of online SD than the Indonesians. In addition, Indonesians also had three times more friends in their network than the Polish.

According to the study by Zywica and Danowski (2008), profile information, photos, the number of friends and the length of the user's wall are also indicative of the self-perceived popularity (Zywica and Danowski, 2008). Users who have higher numbers of friends, often change their profile information and upload impressive pictures are perceived as more popular (Zywica and Danowski, 2008). Additionally, Nadkarni and Hofmann (2012) implied that the profile information may reflect the public persona of the user - a certain image created to impress the audience by uploading some specific information, choosing and changing the profile photo and displaying the number of friends.

This finding may indicate that the desire for impression formation in Facebook is stronger for Indonesian users than for Polish. But it could be a sign that in a hierarchical individualist culture, like Polish, sharing information excessively is considered as more risky (Reisinger and Turner, 1997) and may make users feel uneasy (Hofstede, 2014b) in comparison to people in collectivist cultures.

This study has also found that the Polish are likely to have more positive contents of $\mathrm{SD}$ than the Indonesian users. The effect size in this factor was small, but this finding seems in line with the past study conducted by Graham et al. (2008), where it was demonstrated that the tendency to disclose negative emotions is related to the greater number of social ties and intimacy seeking. Graham et al. (2008) noted that revealing negative emotions could be associated with building relationships by attracting the attention of particular people. Similarly, Indonesians maintained a wider online network and had a larger number of Facebook friends compared to the Polish. Thus, this result might imply that Indonesians seek more intimacy in SNS compared to the Poles.

The other possibility why Indonesian displayed less positive contents of SD might be related to the cultural differences between individualist and collectivist cultures, regardless of the similarity of unequal distribution of power distance in both societies. Diener and Diener (1995) said people in individualist cultures tend to like themselves. Contrarily, showing positivity about self might be a sign of maladjustment in collectivist cultures (Diener and Diener, 1995). Hence, the more individualist the culture, the more people will need to feel positive about themselves. As "self" is not defined as self-contained and independent in collectivist cultures, it is more interdependent and context-dependent in social circumstances (Markus and Kitayama, 1991; Tafarodi and Walters, 1999).

The difference between the concept of "self" within those two types of cultures implies that collectivists usually get lower results on SE measures compared to individualists (Tafarodi and Walters, 1999). This study has also confirmed that Indonesians' SE levels are lower than those of the Polish.

This study has found that NfP and profile availability seemed to have a significant relationship with the amount of SD. However, the coefficient correlations between those factors indicated no significant differences across nationalities. This shows that the higher the level of NfP, the more people disclose on the Internet.

Furthermore, the result in this study show that users who have a more accessible profile page tend to disclose more frequently on Facebook. Zywica and Danowski (2008) implied that people who crave popularity tend to update more frequently and post new information on their walls more often; some of them might even manipulate information to gain popularity.
How do Polish and Indonesian disclose in Facebook? 
JICES

12,3

210
In addition, the study by Christofedes et al. (2009) indicated that having an online existence and being connected on SNS are conditions perceived as necessary to reach popularity among peer groups. Individuals with a high NfP may not be willing to sacrifice their popularity by lowering the accessibility of personal information and limiting their expression on Facebook (Christofedes et al., 2009).

Moreover, people who protect their online information to a lesser degree are likely to display higher levels of SD in SNS. The significant relationship between depth/intimacy of SD, both factors of NfP and profile availability across nationalities support these assumptions. Hence, people keep disclosing intimate information on Facebook for the sake of popularity.

However, the relationship of intimacy of SD to NfP was at different strength levels across the groups. The discrepancies also occurred between the depth/intimacy of SD and profile availability. Those relationships had higher correlations for Indonesians than Poles. The explanation of those results might be related to the nature of NfP, which is not only associated with the people who are socially dominant or salient among others but also related to the display of acceptance-boosting behaviours among users (De Bruyn and Van Den Boom, 2005; Bukowski and Hoza, 1989).

Moreover, maintaining social bonds and relationships seems to play an important role for people in collectivist cultures. Furthermore, NfP is not only related to the display of self-centred behaviour to be the centre of attention but also the other-centred behaviour, in which being highly visible and impressing others helps develop social bonds as well (Tufekci, 2008; Utz et al., 2012).

Another result found in the course of this study is that depth/intimacy and positive contents of online SD were not correlated to NtB. This contradicts previous findings in which online SD was used to fulfil the NtB (Day, 2013). However, the NtB occurs in few relationships (Baumeister and Leary, 1995). Maintaining a friendship in SNS is likely superficial because it often enables the formation of a large friendship network, incorporating strangers or people with whom the users have only weak ties (Utz et al., 2012).

In previous studies, SNS use was driven by the need to be accepted and to be affiliated with others (Gangadharbatla, 2008; Nadkarni and Hoffman, 2012); however, it was conditioned by the existence of a smaller audience, containing only a few intimate friends in the SNS network (Utz et al., 2012).

NtB- and NfP-driven users share a similar desire to be accepted by others and maintain social connections. The difference is that the NfP is fulfilled in huge networks, such as SNS, by being visible, liked and accepted among others (Zywica and Danowski, 2008; Utz et al., 2012), through selective self-presentation and self-promotion. Hence, this study found that almost all dimensions of online SD seem to have more significant results for the NfP than the NtB.

Interestingly enough, the amount of online $\mathrm{SD}$ was related to NtB for the Polish users, but not for the Indonesian. Observing the amount of Polish friendship networks might explain this phenomenon - the Polish had on average only one-third of the number of friends, compared to the Indonesians. It is possible for Poles to maintain online relationships due to the smaller network they possess, providing a higher chance for the Polish to disclose more frequently for only their smaller audience, and to maintain those close friendships.

However, this is not conclusive yet, due to the fact that disclosing depth/intimacy on Facebook seems to have no relation on attaining acceptance for the Polish users. This might point to the existence of a border between public and personal life in individualist societies. 
As a result, those individualist societies exhibiting private/intimate disclosure publicly might be exposed to public ridicule from other users (McKenna and Bargh, 1998).

Online SD of Polish users seemingly tend to be shallower, but they play an important role in maintaining relationships in their small network. However, further research is needed to investigate how the network quality is perceived among users and how they maintain offline friendships through SNS. Users who have smaller networks probably only want to develop online social networks with those whom they already know in offline settings.

The positive content of SD was negatively correlated with NfP for Indonesian users. Revealing negativity on Facebook might imply trust or intimacy-seeking (Graham et al., 2008; Forest and Wood, 2012). This finding is also supported by the results of SE and intimacy of online SD, which were negatively correlated. This indicates that people with less SE will express more intimate SD. For Indonesians, who emphasize maintaining social bonds online, exhibiting intimate information might be one of the self-promotional tools used to gain popularity. The results related to the number of friends and the degree of the disclosure of positive content online, where the Indonesians and Poles were compared, also strengthen this assumption.

Moreover, according to a study by Graham et al. (2008), revealing negative emotions to some extent does not necessarily lead to dismissal or neglect by others, but it could have positive consequences: engaging particular users and ensuring their attention, favour and support. In this way, disclosure of affectively negative information could enhance the relationships with specific people, even when the user has a huge network on Facebook. However, this finding needs to be further explored by examining how the disclosure style of user might be used to maintain particular relationships in SNS.

NfP and positive content of SD were not significantly correlated for Polish users. This might have been because online self-promotion is also related to the sensitivity to one's own network by observing how others present their online public self (Tufekci, 2008). In addition, people in $\mathrm{CMC}$ are more conscious of their disclosure and relatively calculating in the way they present themselves in relation to the other users' own presentation (Walther, 2007).

The perception of the other users' disclosure styles may shape the desirable disclosure content and selective self-presentation. Thus, due to the smaller network and having less online audience, the Polish users may probably observe how their audience presents their public self. Poles might promote themselves to gain popularity by either disclosing positivity or negativity, depending on how they evaluate the self-presentation of others. However, further research is needed to verify the quality of networks and selective self-presentation in regard to the positive content of online $\mathrm{SD}$ and NfP.

Similar result were found both for Polish and Indonesian users concerning SE and positive SD, which were significantly correlated. Forest and Wood (2012) stated that people with higher SE tend to give more positive self-disclosure; on the other hand, people with lower SE tend to disclose more negativity, e.g.: revealing more sadness, anxiety, frustration, fear, anger and irritability and less gratitude, excitement and happiness. Additionally, Zywica and Danowski (2008) implied that people with higher SE have a more positive outlook compared to those who have lower self-esteem.

Interestingly, SE was significantly correlated with the amount of online SD only for the Polish users. On the other hand, SE and depth/intimacy of online SD were significantly correlated for the Indonesian users, but not for Polish. A study by Forest and Wood (2012) showed that people with low SE feel safe to use SNS to disclose information on themselves.
How do Polish and Indonesian disclose in Facebook? 
JICES

12,3

212
Therefore, in both nationalities, the relationship between SE and SD was essentially displayed, despite the fact that it occurred between different dimensions of SD.

For Indonesians, SE might be a matter of how intimately information is disclosed, instead of the frequency of SD. This means that the lower the SE, the more intimate their online SD. Forest and Wood (2012) implied that Facebook may provide an opportunity for people with low SE to develop intimate relationships through self-disclosure. The problematic nature of the need to develop and maintain intimacy in relationships appears to be more salient for Indonesians, compared to the Poles. Indonesia, as a country with a collectivist culture, may prompt openness and intimate/deep SD as methods to maintain contact and togetherness.

This is in line with the social penetration theory which is based on the association between SD and relationship development (Altman and Taylor, 1973). According to Altman and Taylor (1973), as relationships develop, people become more willing to engage in intimate self-disclosure. However, although collectivist cultures emphasize togetherness and depth in communication, they tend to enforce control affective expression in FTF contact, especially in front of figures of authority (Mathews, 2000). Thus, public, excessive disclosure of emotions is too costly in offline interactions. SNS is a platform for people who have lower self-esteem and are either shy or anxious in social settings to express their needs (Forest and Wood, 2012; Qian and Scott, 2007; Valkenburg et al., 2005; McKenna et al., 2002; McKenna and Bargh, 1998). Internet users could be driven by social compensation to fulfil their needs, which is inhibited in offline interaction (Valkenburg et al., 2005).

For the Polish users, SE was more connected to the frequency of online SD instead of how depth/intimate they disclose in SNS. These findings might be connected to the individualist nature of the Polish culture, emphasizing space and privacy (Andersen, 2007). Expression of intimate disclosure publicly is possibly considered to be uneasy, risky and less safe for hierarchical - individualists (Hofstede, 2014b). Therefore, SD and information sharing of the Polish users are rather superficial.

The findings related to the profile availability and the degree of intimate/depth of online SD strengthen this assumption. The Polish profile page is considered to be less accessible, and their disclosure tends to be less intimate. Hence, it is assumed that the Poles who have low SE may still consider the risk of disclose deep/intimate information on Facebook. Although they still use Facebook to disclose frequently and to compensate their need for expression.

Previous studies confirmed that users with low SE usually reveal more of themselves in SNS (Zywica and Danowski, 2008) and are involved in excessive Facebook activity (Mehdizadeh, 2010). However, this study result concerning to SE and online SD needs further investigation; we suspect this phenomenon is related to the hierarchical individualist vis $-\grave{a}$ - vis hierarchical - collectivist differences in compensating their interaction needs, inhibited in real life.

\section{Concluding comments}

6.1 Theory and practical significance

Indonesian (Figure 1) and Polish (Figure 2) Facebook users have different psychological predispositions to online SD. Indonesians belong to a highly collectivist culture and as such were seen as more likely to possess interdependent self-construals (Markus and Kitayama, 1991), emphasize their value of contact (Andersen, 2007) and seek intimacy in 
online environment (Graham et al., 2008) to compensate for their unfulfilled needs in face-to-face (FtF) encounters (Valkenburg et al., 2005).

Moreover, this study verified that Indonesians tend to have huge networks of friends on Facebook. The desire to maintain relationships and belong to a wide network of friends is assumed from the higher NfP and higher availability of profile information of the Indonesian users. As a result, the NfP turned out to be related to each dimension of online SD; at the same time, NtB was not correlated with all of the dimensions of SD. Furthermore, profile availability of Indonesian users also revealed to have a connection with intimacy and the amount of online SD. The interdependent self-construals and the emphasis on intimacy-seeking, present in collectivist cultures, might possibly explain the lower SE levels of Indonesian users, but the association of SE with both intimacy and positive content of online SD cannot be overlooked.

The Polish users were assumed to be a part of a hierarchical - individualist culture and exhibiting several characteristics of such a culture-independent self-construals (Markus and Kitayama, 1991), placing high values on privacy (Andersen, 2007), a certain uneasiness and sensitivity in building new relationships (Hofstede, 2014b) and viewing intimate disclosure as a risky behaviour (Reisinger and Turner, 1997).

At the same time, this study showed the Polish users possessed smaller networks of friends. Maintaining offline relationships through SNS was assumed to be strong motivation for Poles, therefore NtB, NfP as well as profile availability were all correlated with the amount of online SD; no connection with positive content of online SD was present in the current study. The characteristic of hierarchical - individualism in the Polish society might be responsible for the correlations of SE with positive content and frequency of SD.

Overall, several findings of this study present relevant, both practical and theoretical implications for research. Several important theories of what underlies online behaviours
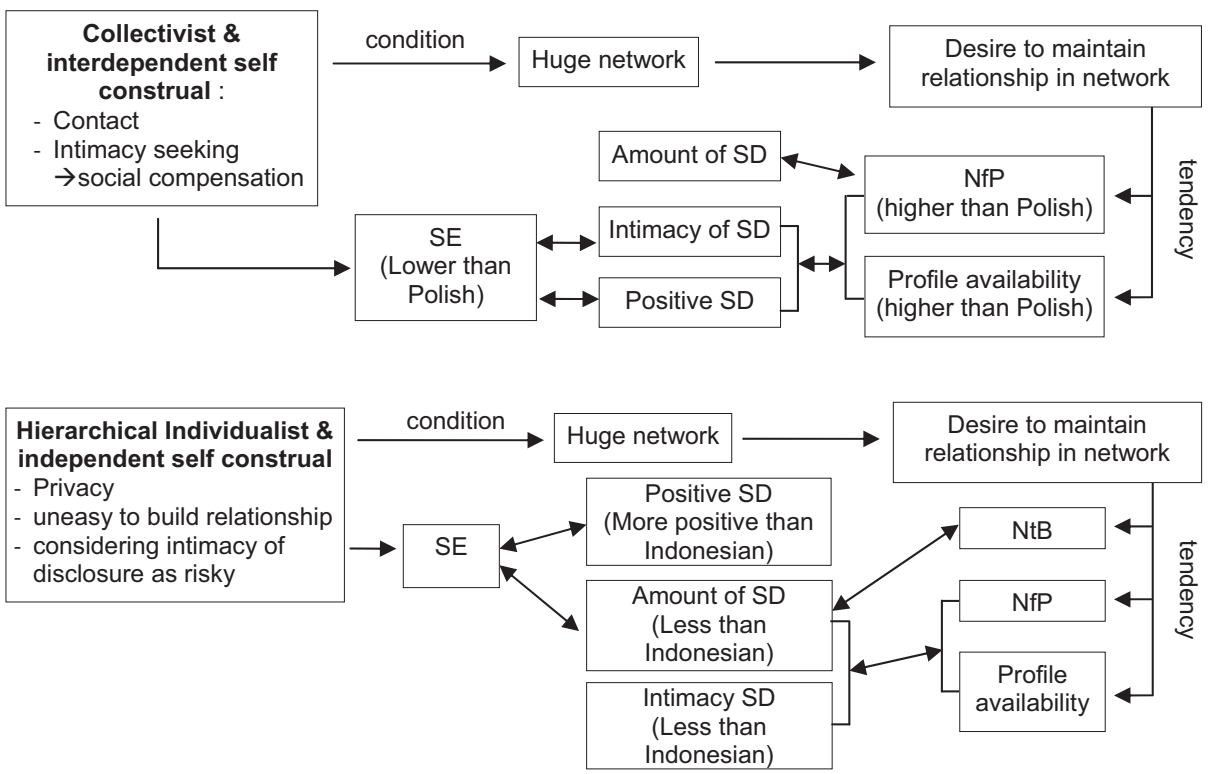

How do Polish and Indonesian disclose in Facebook?

213
Figure 1. Conceptual map and study findings for Indonesian Facebook users
Figure 2.

Conceptual map and study findings for Polish Facebook users 
JICES

12,3

214 were addressed, some of which might require further study. For example, in this study, NtB was not found to be correlated with several of the dimensions of SD, which is, in fact, contradictory to previous research findings; the desire to be affiliated with wide networks seems to have been more connected to $\mathrm{NfP}$ than $\mathrm{NtB}$. However, systematic study is required to further explore the relationship between the size and the quality of friendship networks with psychological factors - such as SD, NtB, NfP and SE - across cultures.

The results of this study also implied that there seem to be differences between individualist and collectivist cultures in the issue of privacy, boundaries and the perception of information as deep/intimate. Further studies would thus include the exploration of privacy issues across cultures.

Considering the existence of different patterns in online SD and the levels of availability of profile pages across cultures, this study could help social network designers in developing features for SNS which are suitable to the psychological needs of users belonging to specific cultures. The current features in SNS may not appeal to all users - further development and augmentation may make the networks more appealing, providing security and comfort to users with consideration to their the cultural backgrounds.

\subsection{Limitations}

There are several limitations to this study. First, there was a problem with the sampling procedure relying on snowball sampling - the method produced disproportional genders ratios, in which participants were predominantly female, especially when it comes to Polish users. Such results limit the validity of the inference to the population from which the sample was drawn. Therefore, the balance proportion of sampling between male and female, as well as the use of selection method that would produce more randomized samples, would require attention in further studies in this field.

Second, SE measured with the current scale may lead to biased responses. According to Diener and Diener (1995), there is a different relevance of SE between collectivist and individualist cultures. Therefore, any further studies would require a broader approach towards SE, incorporating the concepts prevalent in the Eastern collectivist cultures.

Third, the level of culture orientation and power distance in this study was not interpreted based on the primary data from Poland and Indonesia, but rather based on the assumption of differences between individualist and collectivist cultures stemming from the theoretical review. The use of more valid scales of measurement as well as verification of the levels of individualism/collectivism and power distance in particular cultures might be considered in further studies of the subject.

Finally, several findings related to the dimensions of online SD still need to be verified by means of investigating other significant variables to gain a comprehensive explanation of behaviour differences across cultures. For instance, the use of different strategies in online $\mathrm{SD}$, the use of selective self-presentation in the development of particular online relationships in collectivist and individualist cultures; other foreseeable issues include the maintenance of offline relationships through SNS, perception of network quality, choosing audiences within the SNS, the differences in approaching privacy and boundaries online as well as intimate disclosure.

\section{References}

Altman, I. and Taylor, D. (1973), Social Penetration: The Development of Interpersonal Relationships, Holt Rinehart and Winston, New York, NY. 
Andersen, P. (2007), Nonverbal Communication: Forms and Functions (2nd ed.), Waveland Press, IL.

Ardichvili, A. , Maurer, M., Li, W., Wentling, T. and Stuedemann, R. (2006), "Cultural influences on knowledge sharing through online communities of practice", Journal of Knowledge Management, Vol. 10 No. 1, pp. 94-107.

Argyle, M., Hendersona, M., Bondb, M., Iizukac, Y. and Contarellod, A. (1986), "Cross-cultural variations in relationships rules", International Journal of Psychology, Vol. 21 Nos 1/4, pp. 287-315.

Baumeister, R.F. and Leary, M.R. (1995), "The need to belong: desire for interpersonal attachments as a fundamental human motivation”, Psychological Bulletin, Vol. 117 No. 3, pp. 497-529.

Becker, J.A.H. and Stamp, G.H. (2005), "Impression management in chat rooms: a grounded theory model", Communication Studies, Vol. 56 No. 3, pp. 243-260.

Boski, P. (2006), "Humanism-materialism: centuries-long polish cultural origins and 20 years of research in cultural psychology”, in Kim, U, Yang, K.-S, Kwang, K.-K (Eds), Indigenous and Cultural Psychology: Understanding People in Context, Springer, New York, NY, pp. 373-403.

Boyd, D.M. (2008), "Why youth (heart) social network sites: the role of networked publics in teenage social life", in Buckingham, D. (Ed), McArthur Foundation series on digital learning - youth, identity, and digital media volume, MIT Press, Cambridge, MA, pp. 119-142.

Bukowski, W.M. and Hoza, B. (1989), "Popularity and friendship: issues in theory, measurement and outcome", in Berndt, T.J. and Ladd, G.W. (Eds), Peer Relationships in Child Development, John Wiley and Sons, New York, NY, pp. 15-45.

Chesney, T. (2005), "Online SD in diaries and its implications for knowledge managers", In UK Academy for Information Systems Conference Proceedings, Northumbria University, 22-24 March.

Christofedes, R., Muise, A. and Desmarais, S. (2009), "Information disclosure and control on Facebook: are they two sides of the same coin or two different processes?”, Cyberpsychology and Behaviour, Vol. 12 No. 3, pp. 341-345.

ConsumerReports.org (2012), "Facebook and your privacy: who sees the data you share on the biggest social network?", available at: www.consumerreports.org/cro/magazine/2012/06/ facebook-your-privacy/index.htm (accessed 28 August 2013).

Day, S. (2013), "Self-disclosure on Facebook: how much do we really reveal?", Journal of Applied Computing and Information Technology, Vol. 17, No. 1, available at: www.citrenz.ac.nz/ jacit/JACIT1701/2013Day_Facebook.html (accessed 17 January 2014).

De Bruyn, E.H. and Van den Boom, D.C. (2005), "Interpersonal behavior, peer popularity and self-esteem in early adolescence", Social Developement, Vol. 14 No. 4, pp. 555-573.

Diener, E. and Diener, M. (1995), "Cross-cultural correlates of life satisfaction and self-esteem", Journal of Personality and Social Psychology, Vol. 68 No. 4, pp. 653-663.

Forbes, G., Zhang, X., Doroszewicz, K and Haas, K. (2009), "Relationships between individualism-collectivism, gender, and direct or indirect aggression: a study in China, Poland and the US", Aggressive Behaviour, Vol. 35 No. 1, pp. 24-30.

Forest, L.A. and Wood, J.V. (2012), "When social networking is not working: individuals with low self-esteem recognize but do not reap the benefits of self-disclosure on Facebook", Psychological science, Vol. 23 No. 3, pp. 1-8.
How do Polish and Indonesian disclose in Facebook?

215 


\section{JICES}

12,3

216

Forgas, J.P. (2011), "Affective influences on self-disclosure: mood effects on the intimacy and reciprocity of disclosing personal information", Journal of Personality and Social Psychology, Vol. 100 No. 3, pp. 449-461.

Gangadharbatla, H. (2008), "Facebook me: collective self-esteem, need to belong, and internet self-efficacy as predictors of the iGeneration's attitudes toward social networking sites", Journal of Interactive Advertising, Vol. 8 No. 2, pp. 5-15.

Gibbs, J.L., Ellison, N.B. and Heino, R.D. (2006), "Self-presentation in online personals, the role of anticipated future interaction, self-disclosure and perceived success in internet dating", Communication Research, Vol. 33 No. 2, pp. 152-177.

GO-gulf.com (2011), "60 Seconds - things that happen on internet every sixty seconds [infographic]”, available at: www.go-gulf.com/blog/60-seconds/ (accessed 3 March 2013).

Gonzales, A.L. and Hancock, J.T. (2011), "Mirror, mirror on my Facebook wall: effects of exposure to Facebook on self-esteem", Cyberpsychology, Behaviour and Social Networking, Vol. 14 Nos 1/2, pp. 79-83.

Govani, T. and Pashley, H. (2005), "Student awareness of the privacy implications while using Facebook", unpublished manuscript. available at: http://lorrie.cranor.org/courses/fa05/ tubzhlp.pdf (accessed 24 June 2013).

Graham, S.M., Huang, J.Y, Clark, M.S and Helgeson, V.S (2008), "The positives of negative emotions: willingness to express negative emotions promotes relationships", Personality and Social Psychology Bulletin, Vol. 34 No. 3, pp. 394-406.

Gretzel, U., Kang, M. and Lee, W. (2008), "Differences in consumer-generated media adoption and use: a cross-national perspective", Journal of Hospitality Marketing and Management, Vol. 17 Nos 1/2, pp. 99-120.

Haferkamp, N. and Krämer, N. (2009), “Creating a digital self: impression management and impression formation on social network sites", in Drotner, K. and Schrøder, K.C. (Eds), Digital Content Creation: Creativity, Competence, Critique, Peter Lang, New York, NY, pp. 129-146.

Hargittai, E. (2008), "Whose space? Differences among users and non-users of social network sites", Journal of Computer-Mediated Communication, Vol. 13 No. 1, pp. 276-297.

Hofstede, G. (2014a), “What about Indonesia”, available at: http://geert-hofstede.com/indonesia. html (accessed 23 March 2014).

Hofstede, G. (2014b), "What about Poland”, available at: http://geert-hofstede.com/poland.html (accessed 22 January 2014).

Joinson, A.N. (2001), "Self-disclosure in computer-mediated communication: the role of self-awareness and visual anonymity”, European Journal of Social Psychology, Vol. 31 No. 2, pp. 177-192.

Jourard, S.M. and Lasakow, P. (1958), "Some factors in self-disclosure", Journal of Abnormal and Social Psychology, Vol. 56 No. 1, pp. 91-98.

Krämer, N.C. and Winter, S. (2008), "Impression management 2.0. The relationship of self-esteem, extraversion, self-efficacy and self-presentation within social networking sites", Journal of Media Psychology, Vol. 20 No. 3, pp. 106-116.

Leary, M.R., Kelly, K.M, Cottrell, C.A and Schreidorfer, L.S. (2012), Individual Differences in the Need to Belong: Mapping the Nomological Network, Unpublished manuscript, Duke University, Durham, NC.

Leary, M.R. and Kowalsky, R.M. (1990), "Impression management: literature review and two component model”, Psychological Bulletin, Vol. 107 No. 1, pp. 34-47.

McKenna, K.Y.A., Green, A.S and Gleason, M.E.J. (2002), "Relationship formation on the internet: what's the big attraction", Journal of Social Issues, Vol. 58 No. 1, pp. 9-13. 
McKenna, K.Y.A. and Bargh, J. (1998), "Coming out in the age of the internet: identity demarginalization through virtual group participation", Journal of Personality and Social Psychology, Vol. 75 No. 3, pp. 681-694.

Markus, H. and Kitayama, S. (1991), "Culture and self: implications for cognition, emotion and motivation”, Psychological Review, Vol. 98 No. 2, pp. 224-253.

Mathews, R. (2000), "Cultural patterns of south Asian and southeast Asian Americans", Journal of Intervention in School and Clinic, Vol. 36 No. 101, pp. 101-104.

Mehdizadeh, S. (2010), "Self-presentation 2.0: narcissism and self-esteem on Facebook", Cyberpsychology, Behavior, and Social Networking, Vol. 13 No. 4, pp. 357-364.

Nadkarni, A. and Hofmann, S.G. (2012), "Why do people use Facebook", Personality and Individual Differences, Vol. 52 No. 3, pp. 243-249.

Nosko, A., Wood, E. and Molema, S. (2010), "All about me: disclosure in online social networking profiles: the case of Facebook", Computers in Human Behavior, Vol. 26 No. 3, pp. 406-418.

Papacharissi, Z. (2009), "Uses and gratifications". in Stacks, D.W. and Salwen, M.B. (eds), An Integrated Approach to Communication Theory and Research 2nd ed., Routledge, New York, NY, pp. 137-152.

Parks, M.R. and Floyd, K. (1996), "Making friends in cyberspace”, Journal of Communication, Vol. 46 No. 1, pp. 80-97.

Qian, H. and Scott, C.R. (2007), "Anonymity and self-disclosure on weblogs", Journal of Computer-Mediated Communication, Vol. 12 No. 4, article 14, available at: http:// jcmc.indiana.edu/vol12/issue4/qian.html (accessed 24 march 2011).

Reisinger, Y. and Turner, L. (1997), "Cross-cultural differences in tourism: Indonesian tourist in Australia”, Journal of Tourism Management, Vol. 18 No 3, pp. 139-147.

Rosenberg, M. (1965), Society and the Adolescent Self-Image, Princeton University Press, Princeton, NJ.

Rubin, R.B., Rubin, A.M. and Martin, M.M. (1993), "The role of self-disclosure and selfawareness in affinity-seeking competence", Communication Research Reports, Vol. 10 No. 2, pp. 107-114.

Santor, D.A., Messervey, D. and Kusumakar, V. (2000), "Measuring peer pressure, popularity, and conformity in adolescent boys and girls: predicting school performance, sexual attitudes, and substance abuse", Journal of Youth and Adolescence, Vol. 29 No. 2, pp. 163-182.

Sheldon, P. (2009), “'I'll poke you. You'll poke me!' Self-disclosure, social attraction, predictability and trust as important predictors of Facebook relationships", Cyberpsychology: Journal of Psychosocial Research on Cyberspace, Vol. 3, No. 2, article 1, available at: http:// cyberpsychology.eu/view.php?cisloclanku $=2009111101 \&$ article $=1$ (accessed 28 August 2013).

Socialbakers (2013), "Facebook statistics by country", available at: www.socialbakers.com/ Facebook-statistics/ (accessed 1 March 2013).

Suler, J.R. (2004), “The online disinhibition effect”, Journal of CyberPsychology and Behavior, Vol. 7 No. 4, pp. 321-326.

Tafarodi, R.W. and Walters, P. (1999), "Individualism-collectivism, life events and self-esteem: a test of two trade-offs", European Journal of Social Psychology, Vol. 29 Nos 5/6, pp. 797-814.

Tidwell, L.C. and Walther, J.B. (2002), "Computer-mediated effects on disclosure, impressions and interpersonal evaluations: getting to know one another a bit at a time", Human Communication Research, Vol. 28 No. 3, pp. 317-348.
How do Polish and Indonesian disclose in Facebook?

217 


\section{JICES}

12,3

218

Tufekci, Z. (2008), "Grooming, gossip, Facebook and myspace”, Information, Communication and Society, Vol. 11 No. 4, pp. 544-564.

Turkle, S. (1995), Life on the Screen: Identity in the Age of the Internet, Simon and Schuster, New York, NY.

Utz, S., Tanis, M. and Vermeulen, I. (2012), "It is all about being popular: the effects of need for popularity on social network site use", Cyberpsychology, Behaviour, and Social Networking, Vol. 15 No. 1, pp. 37-42.

Valente, T.W., Gallaher, P. and Mouttapa, M. (2004), "Using social networks to understand and prevent substance use: a transdisciplinary perspective”, Substance Use and Misuse, Vol. 39 Nos 10/12, pp. 1685-1712.

Valkenburg, P.M. and Peter, J. (2005), “Adolescents' identity experiments on the Internet”, New Media and Society, Vol. 7 No. 3, pp. 383-402.

Vasalou, A., Joinson, A.N. and Courvoisier, D. (2010), "Cultural differences, experience with social networks and the nature of 'true commitment' in Facebook", International Journal of Human-Computer Studies, Vol. 68 No. 10, pp. 719-728.

Walther, J.B. (2007), "Selective self-presentation in computer-mediated communication: hyperpersonal dimensions of technology language and cognition", Computers in Human Behavior, Vol. 23 No. 5, pp. 2538-2557.

Wheeless, L.R. and Grotz, J. (1976), "Conceptualization and measurement of reported self-disclosure", Human Communication Research, Vol. 2 No. 4, pp. 338-346.

Whitty, M. and Joinson, A. (2009), Truth, Lies and Trust on the Internet, Routledge, Hove, East Sussex.

Zywica, J. and Danowski, J. (2008), "The faces of Facebookers: investigating social enhancement and social compensation hypotheses; predicting Facebook and offline popularity from sociability and self-esteem, and mapping the meanings of popularity with semantic networks", Journal of Computer-Mediated Communication, Vol. 14 No. 1, pp. 1-34.

\footnotetext{
About the authors

Rahkman Ardi is lecturer at Department of Personality and Social Psychology, Universitas Airlangga and a PhD Scholar at Faculty of Psychology, University of Warsaw, supported by Directorate General of Higher Education scholarship from the Ministry of Education and Culture of Indonesia. Rahkman Ardi is the corresponding author and can be contacted at: rahkman.ardi@psikologi.unair.ac.id

Dominika Maison is Professor UW at Faculty of Psychology, University of Warsaw, Poland.
}

To purchase reprints of this article please e-mail: reprints@emeraldinsight.com Or visit our web site for further details: www.emeraldinsight.com/reprints 